\title{
Article \\ Whole Blood Thromboelastometry by ROTEM and Thrombin Generation by Genesia According to the Genotype and Clinical Phenotype in Congenital Fibrinogen Disorders
}

\author{
Timea Szanto ${ }^{1,2, *(\mathbb{D})}$, Riitta Lassila ${ }^{1,2}$, Marja Lemponen ${ }^{2}$, Elina Lehtinen ${ }^{1}$, Marguerite Neerman-Arbez ${ }^{3}(\mathbb{D})$ and \\ Alessandro Casini ${ }^{4}$ \\ 1 Unit of Coagulation Disorders, Department of Hematology, Helsinki University Hospital Comprehensive \\ Cancer Center, University of Helsinki, 00029 HUS Helsinki, Finland; riitta.lassila@kolumbus.fi (R.L.); \\ anna-elina.lehtinen@hus.fi (E.L.) \\ 2 Research Program in Systems Oncology in Faculty of Medicine, University of Helsinki, \\ 00029 HUS Helsinki, Finland; marja.lemponen@hus.fi \\ 3 Department of Genetic Medicine and Development, Faculty of Medicine, University of Geneva, \\ 1211 Geneva, Switzerland; Marguerite.Neerman-Arbez@unige.ch \\ 4 Division of Angiology and Hemostasis, University Hospitals of Geneva, 1211 Geneva, Switzerland; \\ Alessandro.Casini@hcuge.ch \\ * Correspondence: timea.szanto@hus.fi; Tel.: +358-44-29-40377
}

check for updates

Citation: Szanto, T.; Lassila, R.; Lemponen, M.; Lehtinen, E.;

Neerman-Arbez, M.; Casini, A. Whole Blood Thromboelastometry by ROTEM and Thrombin Generation by Genesia According to the Genotype and Clinical Phenotype in Congenital Fibrinogen Disorders. Int. J. Mol. Sci. 2021, 22, 2286. https://doi.org/ $10.3390 /$ ijms 22052286

Academic Editor: Peter Hamar

Received: 31 December 2020

Accepted: 22 February 2021

Published: 25 February 2021

Publisher's Note: MDPI stays neutral with regard to jurisdictional claims in published maps and institutional affiliations.

Copyright: (c) 2021 by the authors. Licensee MDPI, Basel, Switzerland. This article is an open access article distributed under the terms and conditions of the Creative Commons Attribution (CC BY) license (https:// creativecommons.org/licenses/by/ $4.0 /)$
Abstract: The outcome of congenital fibrinogen defects (CFD) is often unpredictable. Standard coagulation assays fail to predict the clinical phenotype. We aimed to assess the pheno- and genotypic associations of thrombin generation (TG) and ROTEM in CFD. We measured fibrinogen (Fg) activity and antigen, prothrombin fragments F1+2, and TG by ST Genesia ${ }^{\circledR}$ with both Bleed- and ThromboScreen in 22 patients. ROTEM was available for 11 patients. All patients were genotyped for fibrinogen mutations. Ten patients were diagnosed with hypofibrinogenemia, nine with dysfibrinogenemia, and three with hypodysfibrinogenemia. Among the 17 mutations, eight were affecting the $\mathrm{Fg} \gamma$ chain, four the $\mathrm{Fg} \mathrm{B} \beta$ chain, and five the Fg A $\alpha$ chain. No statistical difference according to the clinical phenotypes was observed among FGG and FGA mutations. Median F1+2 and TG levels were normal among the different groups. Fg levels correlated negatively with F1+2 and peak height, and positively with lag time and time to peak. The pheno- and genotypes of the patients did not associate with TG. FIBTEM by ROTEM detected hypofibrinogenemia. Our study suggests an inverse link between low fibrinogen activity levels and enhanced TG, which could modify the structure-function relationship of fibrin to support hemostasis.

Keywords: congenital fibrinogen defects; thrombin generation by Genesia; ROTEM

\section{Introduction}

Congenital fibrinogen disorders (CFD) are rare disorders affecting either the quantity (afibrinogenemia and hypofibrinogenemia) or the quality (dysfibrinogenemia) or both (hypodysfibrinogenemia) of fibrinogen $(\mathrm{Fg})$ [1]. Hypofibrinogenemia and dysfibrinogenemia are the most frequent types of CFD, characterized by decreased levels of both Fg activity and antigen in the former, and discrepant levels of dysfunctional Fg in the latter. They usually result from heterozygous mutations affecting one of the three fibrinogen genes (i.e., $F G A, F G B$, or FGG) [2]. Hypodysfibrinogenemia is rarely reported. The diagnosis is based not only on a disproportional decrease of activity and antigen Fg levels, but also on specific molecular patterns [3].

The clinical course of CFD is often unpredictable. The clinical manifestations are very heterogeneous, from absence of symptoms to major bleeding or thrombosis (either arterial or venous) and pregnancy-related complications [4,5]. Moreover, asymptomatic individuals at the time of diagnosis may carry a lifetime risk of adverse outcomes. Although 
the diagnosis of most CFD is usually quite straightforward based on standard coagulation assays $[6,7]$, these conventional tests fail to predict the clinical phenotype. Especially, the dysfunctional/abnormal Fg structure in dysfibrinogenemia is poorly assessed by standard coagulation assays. According to the recommendations of the Factor XIII and Fibrinogen Subcommittee of the Scientific Standardization Committee of the ISTH, the classification of CFD should be based on both the clinical phenotype and fibrinogen levels. In addition, specialized research laboratories should complete the fibrinogen work-up, providing insights into the properties of the fibrinogen variants [8].

During the last few years, a growing interest has evolved in the use of global hemostasis assays to measure the dynamics of the entire clotting and fibrinolysis process and to study the risks of bleeding and thrombosis under various clinical settings $[9,10]$. Until now, few attempts have been made to characterize the usefulness of thromboelastography in patients with CFD [11-13]. The influence of fibrinogen level on thrombin generation (TG) has also been investigated [14]. However, data in the setting of CFD—notably qualitative fibrinogen disorders - have limited to very few case reports [15].

Lately, a new TG analyzer (ST Genesia ${ }^{\circledR}$, Stago) has been released as the first fully automated TG method for clinical routine laboratories. ST Genesia ${ }^{\circledR}$ offers a set of reagents balanced for sensitivity to procoagulant and anticoagulant protein deficiencies [16].

We aimed to assess the clinical outcome by studying TG by ST Genesia ${ }^{\circledR}$ and ROTEM in relation to various phenotypes, and to explore whether the clinical phenotypes are associated with genetic mutations.

\section{Results}

A total of 22 patients, 12 from Finland and 10 from Switzerland, were included. The median age of patients was 43.5 years (range 21-83 years). Most of the patients were female $(77.3 \%)$. Fourteen patients were unrelated.

The clinical features, genotypes and Fg levels of the patients are presented in Table 1.

Nine patients were diagnosed with hypofibrinogenemia based on concordant Fg activity and antigen levels (ratios > 0.7), with median Fg activity level of $0.8 \mathrm{~g} / \mathrm{L}$ (range $0.45-1.0 \mathrm{~g} / \mathrm{L}$ ) and median Fg antigen level of $1.0 \mathrm{~g} / \mathrm{L}$ (range $0.40-1.2 \mathrm{~g} / \mathrm{L}$ ). Ten patients were diagnosed with dysfibrinogenemia based on discordant $\mathrm{Fg}$ activity and antigen levels (ratios <0.7), with median Fg activity level of $0.9 \mathrm{~g} / \mathrm{L}$ (range $0.40-1.40 \mathrm{~g} / \mathrm{L}$ ) and median Fg antigen level of $2.40 \mathrm{~g} / \mathrm{L}$ (range 1.80-3.10 g/L). In three patients, a definitive diagnosis of hypodysfibrinogenemia was confirmed upon genetic analysis. Their median Fg activity level was $0.8 \mathrm{~g} / \mathrm{L}$ (range 0.70-1.08 g/L) and median Fg antigen level was $1.60 \mathrm{~g} / \mathrm{L}$ (range $1.40-1.80 \mathrm{~g} / \mathrm{L}$ ). Bleeding tendency was classified with a bleeding score $>3$, which occurred in $5 / 22(22.7 \%)$ patients, including three hypofibrinogenemia and two dysfibrinogenemia patients. Bleeding symptoms included menorrhagia $(n=5)$, vaginal bleeding during pregnancy $(n=1)$, bleeding after injury $(n=1)$, hemarthrosis $(n=1)$, postsurgical hemorrhage $(n=3)$. Two patients had only thrombotic complications $(9 \%)$. One female with hypofibrinogenemia (HEL 1.3), obesity, and type 2 diabetes experienced a provoked deep venous thrombosis (DVT) and was treated with warfarin for three months. A patient with dysfibrinogenemia (HEL 2.1), obesity and dyslipidemia developed unprovoked pulmonary embolisms (PE) and DVT of the upper limb and was commenced on lifelong anticoagulant therapy with warfarin. Two patients had both bleeding and thrombotic complications. One female with hypodysfibrinogenemia (GEN 7) suffered from provoked PEs following a hysterectomy due to menorrhagia. She was treated by three months of low molecular weight heparin (LMWH). Another female with hypofibrinogenemia (HEL 3.1) and obesity experienced DVT of the right lower limb during intake of oral contraceptive at the age of 18, and later at the age of 36 two unprovoked DVTs, one of the left lower extremity, and three months later left iliofemoral DVT despite warfarin therapy. For the latest, she underwent iliac vein stenting under fibrinogen supplementation (Riastap, CSL Behring) and received a long-term antithrombotic treatment with $\mathrm{LMWH}$ and aspirin. She also suffered from menorrhagia but gave birth three times without major bleeding complications. She received 
LMWH prophylaxis throughout her pregnancies and pospartum up to 6 weeks. Thirteen patients were asymptomatic, of which $4 / 22(18.2 \%)$ had hypofibrinogenemia, $7 / 22(31.8 \%)$ dysfibrinogenemia, and 2/22 (9\%) hypodysfibrinogenemia (Table 1 ).

Table 1. Clinical manifestations, genotypes, and phenotypic characteristics according to traditional fibrinogen assays.

\begin{tabular}{|c|c|c|c|c|c|c|c|c|c|c|}
\hline & Patient & Age & Gender & Phenotypes & $\begin{array}{l}\text { Fg } \\
\text { Act }\end{array}$ & $\begin{array}{l}\mathrm{Fg} \\
\mathrm{Ag}\end{array}$ & Type & Gene & Mutation & $\begin{array}{l}\text { Family } \\
\text { Members }\end{array}$ \\
\hline \multirow{3}{*}{ Family 1} & HEL 1.1 & 72 & Female & Asymptomatic & 1.3 & 1.3 & Нyро $^{1}$ & $\begin{array}{l}F G G, \\
\text { exon } 8\end{array}$ & $\begin{array}{l}\text { het Thr303Pro and } \\
\text { het Asp327His }\end{array}$ & Thrombosis \\
\hline & HEL 1.2 & 24 & Male & Asymptomatic & 0.7 & 0.7 & Hypo $^{1}$ & $\begin{array}{l}F G G \\
\text { exon } 8\end{array}$ & $\begin{array}{l}\text { het Thr303Pro and } \\
\text { het Asp327His }\end{array}$ & \\
\hline & HEL 1.3 & 48 & Female & Thrombosis & 1.0 & 1.2 & Нypo $^{1}$ & $\begin{array}{l}F G G \\
\text { exon } 8\end{array}$ & $\begin{array}{l}\text { het Thr303Pro and } \\
\text { het Asp327His }\end{array}$ & \\
\hline \multirow{3}{*}{ Family 2} & HEL 2.1 & 82 & Male & Thrombosis & 1.2 & 2.5 & Dys $^{2}$ & $\begin{array}{l}F G G, \\
\text { exon } 8\end{array}$ & het Tyr306Cys & Thrombosis \\
\hline & HEL 2.2 & 58 & Male & Asymptomatic & 1.6 & 2.5 & Dys $^{2}$ & $\begin{array}{l}F G G \\
\text { exon } 8\end{array}$ & $\begin{array}{l}\text { homozygous } \\
\text { Tyr306Cys }\end{array}$ & \\
\hline & HEL 2.3 & 83 & Male & Asymptomatic & 1.7 & 3.5 & Dys $^{2}$ & $\begin{array}{l}F G G \\
\text { exon } 8\end{array}$ & het Tyr306Cys & \\
\hline \multirow{2}{*}{ Family 3} & HEL 3.1 & 40 & Female & $\begin{array}{l}\text { Bleeding and } \\
\text { thrombosis }\end{array}$ & 1.0 & 1.7 & Hypo $^{1}$ & $\begin{array}{l}F G G, \\
\text { exon } 8\end{array}$ & $\begin{array}{l}\text { het Thr303Pro and } \\
\text { het Asp327His }\end{array}$ & $\begin{array}{l}\text { Bleeding and } \\
\text { thrombosis * }\end{array}$ \\
\hline & HEL 3.2 & 30 & Female & Bleeding & $<1$ & 0.7 & Hypo $^{1}$ & $\begin{array}{l}F G G, \\
\text { exon } 8\end{array}$ & $\begin{array}{l}\text { het Thr303Pro and } \\
\text { het Asp327His }\end{array}$ & \\
\hline \multirow{14}{*}{$\begin{array}{l}\text { Not } \\
\text { related }\end{array}$} & HEL 4 & 35 & Female & Asymptomatic & 0.8 & 1.8 & Hypodys ${ }^{3}$ & $\begin{array}{l}F G G, \\
\text { exon } 9\end{array}$ & het Trp395Leu & Thrombosis \\
\hline & HEL 5 & 38 & Female & Asymptomatic & $<1$ & 2.6 & Dys ${ }^{2}$ & $\begin{array}{l}F G G, \\
\text { exon } 9\end{array}$ & $\begin{array}{l}\text { het c.1283-1284 } \\
\text { del TG }\end{array}$ & Thrombosis \\
\hline & HEL 6 & 43 & Female & Asymptomatic & 1.9 & 2.4 & Dys $^{2}$ & $\begin{array}{l}F G A, \\
\text { exon } 2\end{array}$ & het Leu28Pro & NA \\
\hline & HEL 7 & 47 & Female & Bleeding & $<1$ & 1.0 & Hypo $^{1}$ & $\begin{array}{l}F G G \\
\text { exon } 9\end{array}$ & het Thr397Ile & Bleeding \\
\hline & GEN 1 & 37 & Female & Bleeding & 0.6 & 2.4 & Dys ${ }^{2}$ & $F G G$ & Arg301His & Bleeding \\
\hline & GEN 2 & 39 & Female & Asymptomatic & 0.5 & 1.8 & Dys $^{2}$ & $F G B$ & $\begin{array}{l}\text { c.402_410 del } \\
\text { GGAAGCTGT }\end{array}$ & NA \\
\hline & GEN 3 & 49 & Female & Bleeding & 0.7 & 2.1 & Dys $^{2}$ & $F G A$ & Arg $35 \mathrm{His}$ & Bleeding \\
\hline & GEN 4 & 30 & Male & Asymptomatic & 0.7 & 1.4 & Нypo $^{1}$ & $F G B$ & Thr407Met & Bleeding \\
\hline & GEN 5 & 51 & Male & Asymptomatic & 0.5 & 2.8 & Dys $^{2}$ & $F G A$ & Arg38Gly & Asymptomatic \\
\hline & GEN 6 & 44 & Male & Asymptomatic & 1.1 & 1.2 & Нуро $^{1}$ & $F G G$ & Arg375Trp & Asymptomatic \\
\hline & GEN 7 & 57 & Female & $\begin{array}{l}\text { Bleeding and } \\
\text { thrombosis }\end{array}$ & 1.1 & 1.8 & Hypodys $^{3}$ & $F G B$ & Arg285Leu & Bleeding \\
\hline & GEN 8 & 31 & Male & Asymptomatic & 0.4 & 0.4 & Hypo $^{1}$ & $F G A$ & $11 \mathrm{~kb}$ del & Asymptomatic \\
\hline & GEN 9 & 53 & Female & Asymptomatic & 0.6 & 3.1 & Dys $^{2}$ & $F G A$ & Arg35His & NA \\
\hline & GEN 10 & 21 & Female & Bleeding & 0.9 & 1.0 & Hypo $^{1}$ & $F G B$ & Arg294Ser & Asymptomatic \\
\hline
\end{tabular}

${ }^{1}$ Hypofibrinogenemia, ${ }^{2}$ Dysfibrinogenemia, ${ }^{3}$ Hypodysfibrinogenemia.

Genetic analyses identified 14 missense mutations in 19 patients from 14 unrelated families, and three deletions in the remaining three patients. As shown in Table 1, almost all Finnish patients had missense mutations clustered in exons 2, 8, or 9 of FGG. The same double heterozygous FGG mutations, most likely carried on the same chromosome, p.Thr303Pro and p.Asp327His were discovered in two unrelated families (families 1 and $3, n=5)$. In family 2 , the FGG p.Tyr306Cys mutation was identified in both heterozygous and homozygous form. Interestingly, the patient HEL 2.2 with the homozygote form of the mutation was asymptomatic, while the patient 2.1 with the heterozygote form had thrombotic complications. More heterogeneous distribution was observed in the Swiss patients. Four had mutations affecting the $\mathrm{Fg} A \alpha$ chain, four the $\mathrm{Fg} \mathrm{B} \beta$ chain and three the Fg $\gamma$ chain. Of note, the asymptomatic patient GEN 6 had a mutation in FGG exon 8 p.Arg375Trp which is the causative mutation of fibrinogen Aguadilla, associated with a fibrinogen storage disease [17]. No statistical difference according to the clinical phenotypes was observed among FGG and FGA mutations. 


\subsection{Thrombin Generation}

TG variables by ST Genesia ${ }^{\circledR}$ (STG-BLS and STG-TS) are reported as normalized (Table 2) and absolute values (Figures 1-3). Patients 2.1 and 3.1 with long-term anticoagulation and antiplatelet therapy were excluded from this study. None of the patients received oral contraception or hormonal therapy during the TG studies.

Table 2. Mean normalized TG variables with STG-BLS and STG-TS in the absence of thrombomodulin according to clinical and laboratory phenotypes.

\begin{tabular}{|c|c|c|c|c|}
\hline STG-BLS Normalized & $\begin{array}{l}\text { Lag Time, Ratio } \\
\text { (Range) }\end{array}$ & ETP, \% (Range) & $\begin{array}{c}\text { Peak Height, \% } \\
\text { (Range) }\end{array}$ & $\begin{array}{c}\text { Time to Peak, Ratio } \\
\text { (Range) }\end{array}$ \\
\hline Hypofibrinogenemia $(n=8)$ & $1.2(0.9-1.4)$ & $82.7(41.6-101.5)$ & $88,5(30.6-113.2)$ & $1.1(1.0-1.4)$ \\
\hline Dysfibrinogenemia $(n=8)$ & $1.1(0.8-2.0)$ & $80.4(49.2-111.2)$ & $81.4(46.6-104.5)$ & $1.1(0.9-1.7)$ \\
\hline Hypodys-fibrinogenemia $(n=3)$ & $1.0(1.0-1.6)$ & $83.0(49.2-105.0)$ & $81.4(39.2-121.7)$ & $1.1(1.0-1.3)$ \\
\hline Reference range * & $0.9-1.3$ & $57-114$ & $51-99$ & $0.9-1.3$ \\
\hline STG-TS-TM Normalized & $\begin{array}{l}\text { Lag Time, Ratio } \\
\text { (Range) }\end{array}$ & ETP, \% (Range) & $\begin{array}{l}\text { Peak Height, \% } \\
\text { (Range) }\end{array}$ & $\begin{array}{c}\text { Time to Peak, Ratio } \\
\text { (Range) }\end{array}$ \\
\hline Hypofibrinogenemia $(n=8)$ & $1.1(0.9-1.3)$ & $79.0(46.3-90.5)$ & $75.1(32.7-90.0)$ & $1.2(1.1-1.7)$ \\
\hline Dysfibrinogenemia $(n=8)$ & $1.1(0.8-2.2)$ & $65.0(48.1-96.5)$ & $62.2(33.7-78.8)$ & $1.2(0.9-2.0)$ \\
\hline Hypodys-fibrinogenemia $(n=3)$ & $1.1(1.1-1.5)$ & $80.8(52.9-83.1)$ & $65.5(28.8-89.1)$ & $1.2(1.1-1.6)$ \\
\hline Reference range* & $1.0-1.3$ & $59-99$ & $45-102$ & $1.0-1.5$ \\
\hline
\end{tabular}

* Reference range as according to the literature [16].

\section{Bleedscreen}
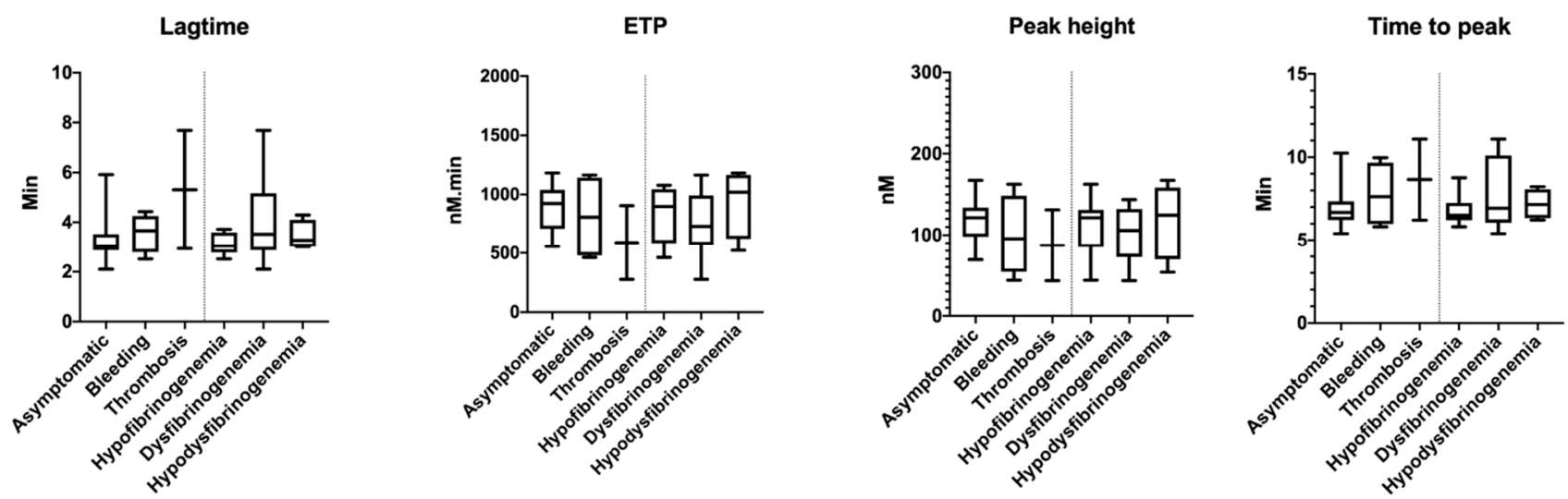

Figure 1. Mean TG variables with STG-BLS (bleedscreen) according to clinical and laboratory phenotypes. TG values are shown for 19 patients as follows: asymptomatic $n=13$; bleeding $n=4$, thrombosis $n=2$; hypofibrinogenemia $n=8$; dysfibrinogenemia $n=8$ and hypodysfibrinogenemia $n=3$. 


\section{Thromboscreen}
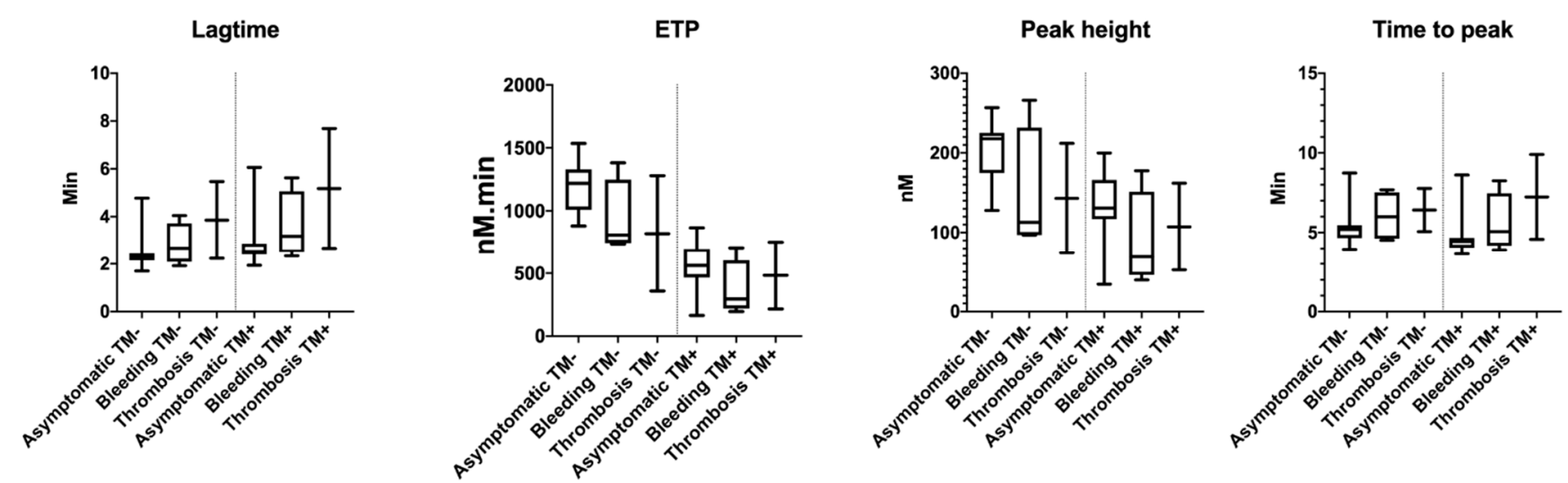

Figure 2. Mean TG variables with STG-TS (thromboscreen) according to clinical phenotype and the supplementation of TM. TG values are shown for 19 patients as follows: asymptomatic $n=13$; bleeding $n=4$, thrombosis $n=2$; hypofibrinogenemia $n=8$; dysfibrinogenemia $n=8$; and hypodysfibrinogenemia $n=3$.

\section{Thromboscreen}
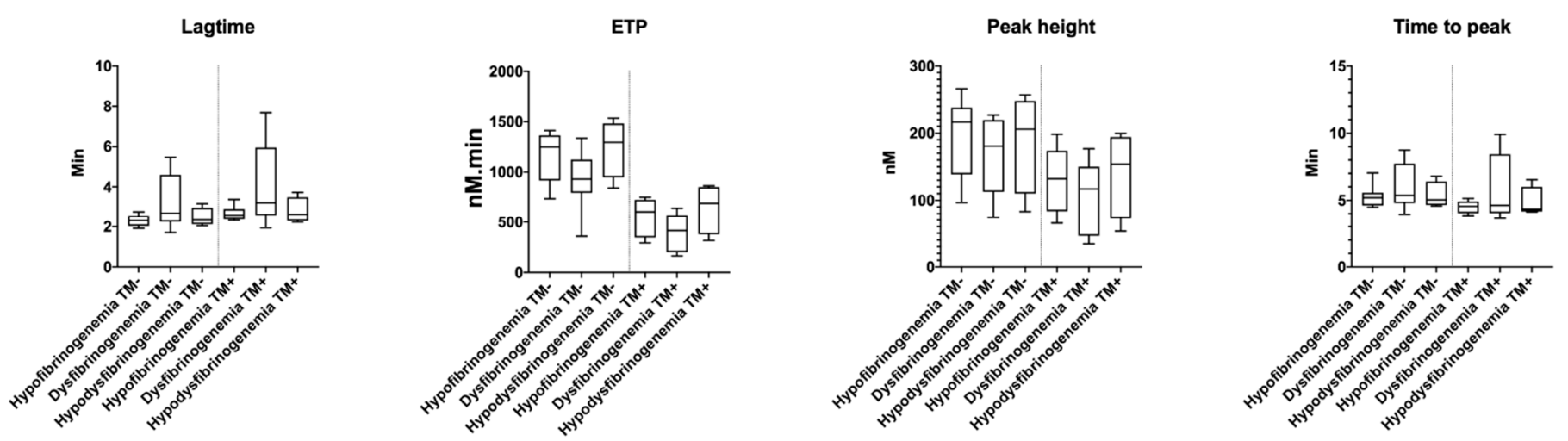

Figure 3. Mean TG variables with STG-TS (thromboscreen) according to laboratory phenotype and the supplementation of TM. TG values are shown for 19 patients as follows: asymptomatic $n=13$; bleeding $n=4$, thrombosis $n=2$; hypofibrinogenemia $n=8$; dysfibrinogenemia $n=8$; and hypodysfibrinogenemia $n=3$.

All median TG levels were within the normal reference range [16]. The inter-individual variation was up to 6-fold for peak height and up-to 5-fold for ETP among patients with STG-TS in the presence of thrombomodulin (TM). Variations were dependent on the clinical phenotype or Fg levels. The largest CV was observed for the peak height among asymptomatic patients and dysfibrinogenemia (6-fold and 5-fold as compared to 3-fold variation in normal donors).

In STG-BLS, lag time correlated positively with Fg activity $(\mathrm{r}=0.6, p=0.03)$, the peak height and ETP negatively with fibrinogen activity $(r=-0.6, p=0.03$ and $\mathrm{r}=-0.7$, $p<0.0001$, respectively; Figure 4). In STG-TS with TM, there was a positive correlation between lag time, time to peak and Fg activity $(\mathrm{r}=0.6, p<0.002$ and $\mathrm{r}=0.5, p<0.01)$ and a negative correlation between both ETP and Fg activity $(r=-0.5, p=0.03$, and $\mathrm{r}=-0.5$ and $p=0.02$ ). However, the subgroup analysis according to the type of CFD and the clinical phenotype did not reveal any difference between the groups nor statistical difference between TG variables, clinical phenotype, type of CFD, and presence of TM (Figures 1-3; data shown as absolute values). 


\section{Bleedscreen}
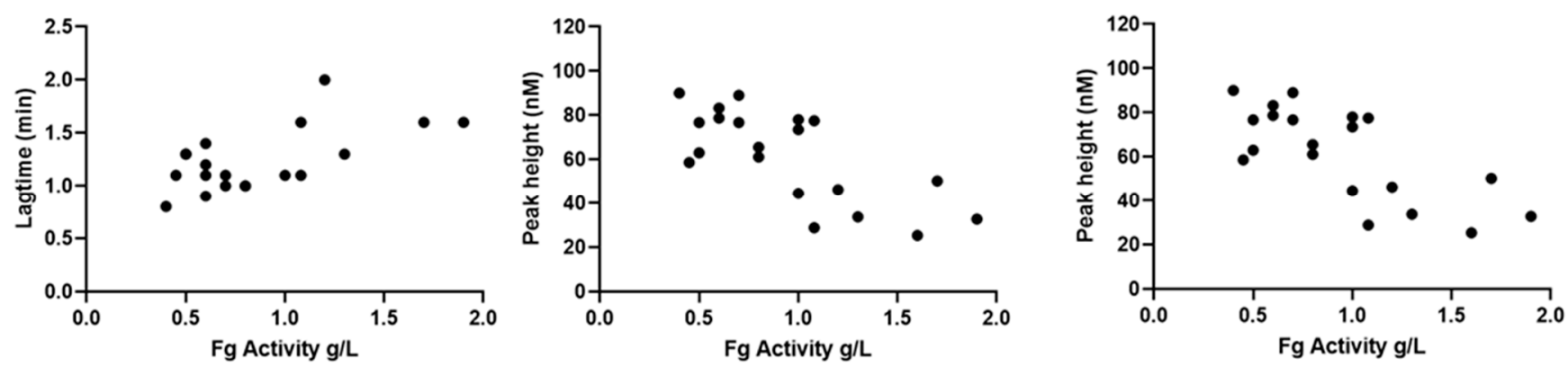

Figure 4. Correlation of TG variables with STG-BLS (bleedscreen) with fibrinogen activity. The data are shown TG values are shown for 19 patients as follows: asymptomatic $n=13$; bleeding $n=4$, thrombosis $n=2$; hypofibrinogenemia $n=8$; dysfibrinogenemia $n=8$; and hypodysfibrinogenemia $n=3$.

There was no correlation among all the variables tested when comparing dysfibrinogenemic mutations affecting the thrombin binding site at the $\mathrm{N}$-terminal end of the fibrinogen $\mathrm{A} \alpha$ chain ( $F G A$ exon 2) to mutations affecting the end-to-end alignment of fibrinogen or fibrin molecules in assembling polymers ( $F G G$ exon 8).

\subsection{In Vivo Thrombin Generation}

F1+2 fragment levels varied between 82 and $552 \mathrm{pM}$ (reference 69-229 pM), indicating normal to somewhat increased in vivo TG (data not shown). The inter-individual variation was up to 7-fold among the patients. We demonstrated a negative correlation between $\mathrm{F} 1+2$ and both $\mathrm{Fg}$ antigen $(\mathrm{r}=-0.3, p<0.006)$ and activity $(\mathrm{r}=-0.8, p=<0.0001)$ levels (Figure 5). We further demonstrated a negative correlation between F1+2 and lag time by both STG-BLS $(\mathrm{r}=-0.3, p<0.0003)$ and STG-TS in the absence of TM $(\mathrm{r}=-0.24$, $p<0.001)$. The subgroup analysis according to CFD and clinical phenotype did not reveal any difference between the groups (Figure 6).
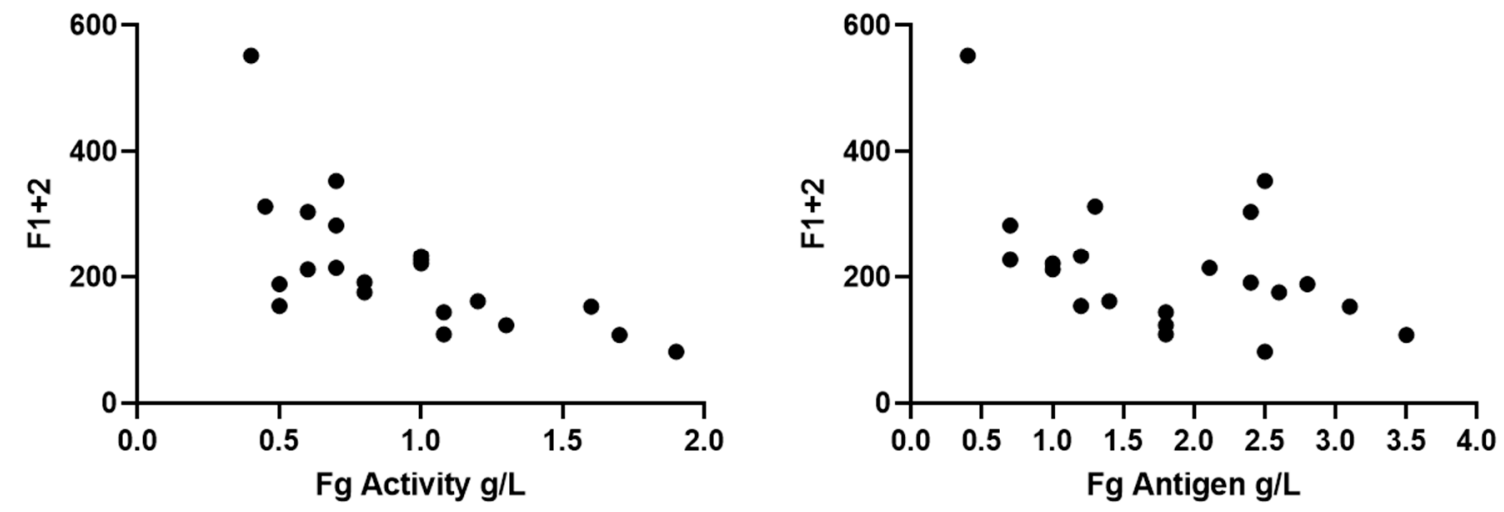

Figure 5. Correlation of F1+2 levels with Fibrinogen activity and antigen. Data are shown for 20 patients as follows: asymptomatic $n=13$; bleeding $n=5$, thrombosis $n=2$; hypofibrinogenemia $n=9$; dysfibrinogenemia $n=8$ and hypodysfibrinogenemia $n=3$. 


\section{F1-2}

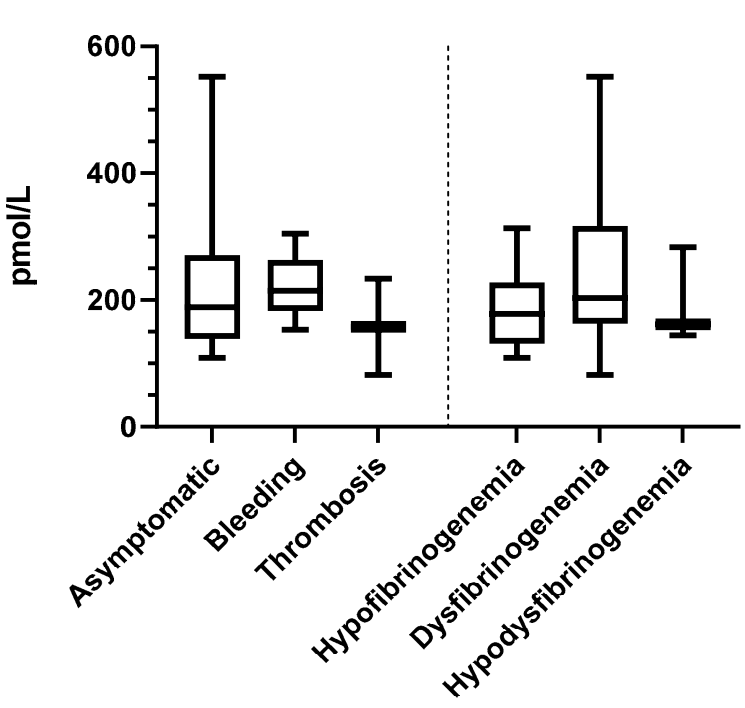

Figure 6. Mean F1+2 levels according to the clinical and laboratory phenotypes. F1+2 values are shown for 20 patients as follows: asymptomatic $n=13$; bleeding $n=5$, thrombosis $n=2$; hypofibrinogenemia $n=9$; dysfibrinogenemia $n=8$; and hypodysfibrinogenemia $n=3$.

\subsection{ROTEM}

ROTEM analysis was carried out in 11 patients (7 hypo- and 5 dysfibrinogenemia, all from Finland) using the standard reagents. In hypofibrinogenemia, $\mathrm{CT}$ and MCF were markedly abnormal (Figure 7A). Median CT in hypofibrinogenemia compared with dysfibrinogenemia patient was $233 \mathrm{~s}$ (range 81-5414 s) vs. $55 \mathrm{~s}$ (range 50-132) ( $p=0.0303$ ). Median CT in hypofibrinogenemia was $76 \%$ prolonged as compared with dysfibrinogenemia. Median MCF in hypofibrinogenemia compared with dysfibrinogenemia patient was $4 \mathrm{~mm}$ (range $0-6 \mathrm{~mm}$ ) vs. $13 \mathrm{~mm}$ (range 11-24 mm) $(p=0.0022)$, corresponding to $69 \%$, lowered value in dysfibrinogenemia. MCF by FIBTEM correlated with Fg antigen $(\mathrm{r}=0.6, p=0.006)$ but not with activity $(\mathrm{r}=-0.2, p=0.4)$. Moreover, there was a statistical difference among the patient's clinical phenotype for the FIBTEM CT $(p=0.0003)$.

Median CT and MCF were all normal by EXTEM, INTEM, and APTEM. Median MCF in hypofibrinogenemia compared with dysfibrinogenemia patients was significantly reduced in all other ROTEM tests as follows: EXTEM hypofibrinogenemia $49 \mathrm{~mm}$ (below normal range) vs dysfibrinogenemia $61 \mathrm{~mm}(p=0.003$; normal range 58-63 $\mathrm{mm})$, INTEM hypofibrinogenemia $48 \mathrm{~mm}$ (below normal) vs. dysfibrinogenemia $60 \mathrm{~mm}(p=0.004$; normal range 59-64 $\mathrm{mm}$ ) and APTEM hypofibrinogenemia $52 \mathrm{~mm}$ vs. dysfibrinogenemia $62 \mathrm{~mm}(p=0.007$; normal range 50-72 mm (Figure 7B). We observed a strong uniform negative correlation between Fg activity and in overall MCFs by EXTEM $(r=-0.6, p=0.004)$, $\operatorname{INTEM}(\mathrm{r}=-0.6, p=0.004)$ and APTEM $(\mathrm{r}=-0.7, p=0.002)$. A weaker negative correlation between Fg antigen and MCF by EXTEM $(\mathrm{r}=-0.5, p=0.01)$, INTEM $(\mathrm{r}=-0.5, p=0.01)$, and APTEM $(\mathrm{r}=-0.6, p=0.009)$ was also found. 

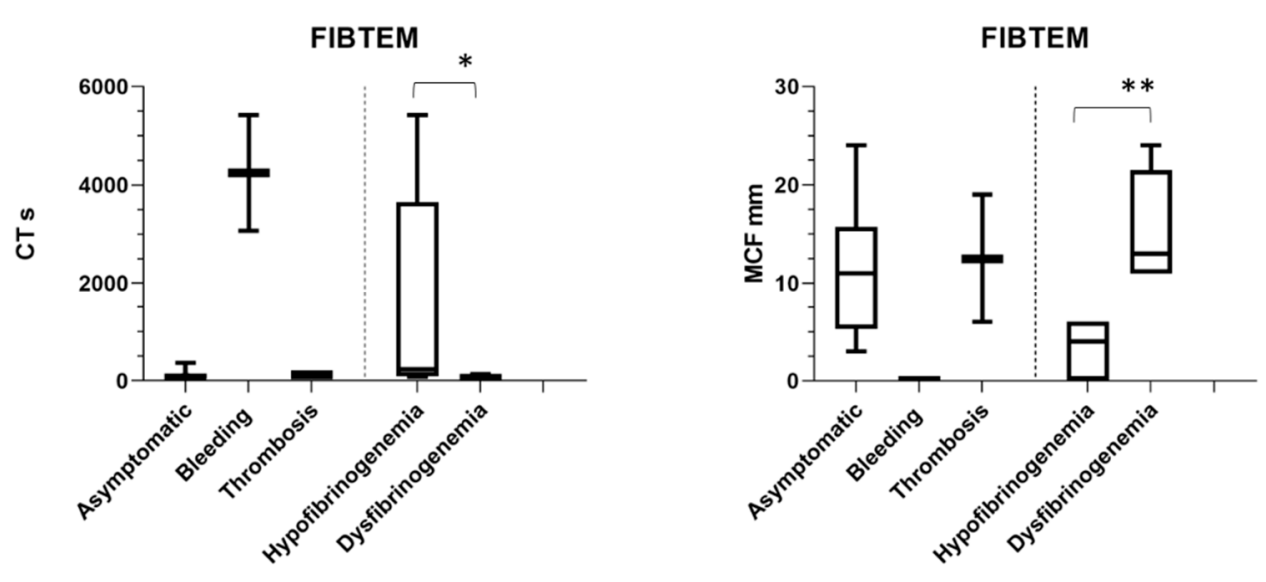

B
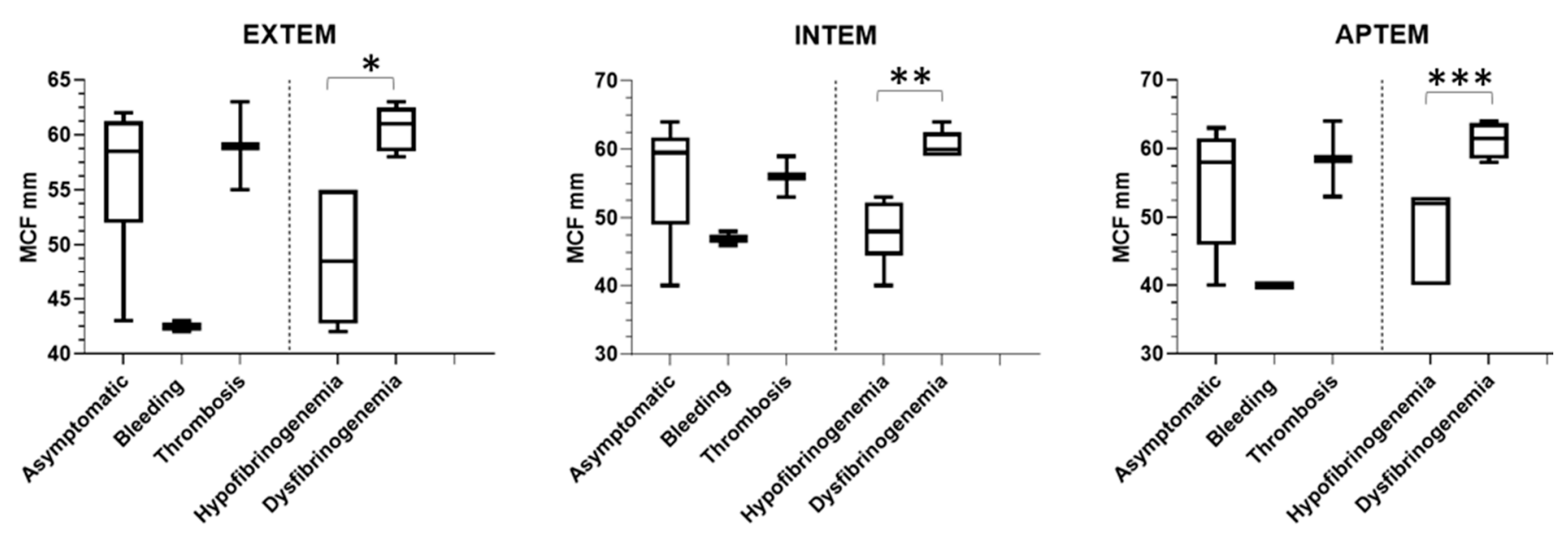

Figure 7. ROTEM profiles according to clinical and laboratory phenotypes. (A). FIBTEM CT and MCF are shown for 110 patients as follows: asymptomatic $n=7$; bleeding $n=2$, thrombosis $n=2$; dysfibrinogenemia $n=6$ and dysfibrinogenemia $n=5$. ${ }^{*} \mathrm{CT}$ was markedly prolonged in hypo- in comparison with dysfibrinogenemia $(p=0.0303)$. ${ }^{* *}$ Fibrin polymerization capacity (clot firmness) in FIBTEM was decreased (MCF $\leq 6 \mathrm{~mm}$ ) in hypofibrinogenemia as compared with dysfibrinogenemia $(p=0.0022)$. (B). EXTEM, INTEM, and APTEM MCF are shown for 11 patients as follows: asymptomatic $n=7$; bleeding $n=2$, thrombosis $n=2$; dysfibrinogenemia $n=6$; and dysfibrinogenemia $n=5$ MCF was markedly decreased in hypo- in comparison with dysfibrinogenemia in EXTEM $(* p=0.003), \operatorname{INTEM}(* * p=0.004)$, and APTEM $(* * * p=0.007)$.

\section{Discussion}

In this study, we investigate for the first time the TG by ST Genesia ${ }^{\circledR}$ in CFD and correlated biological and clinical phenotypes with ROTEM parameters. We observed a significant correlation between Fg levels and TG, both with ST Genesia ${ }^{\circledR}$ in vitro and prothrombin fragments F1+2 reflecting FXa in vivo. An important association between the laboratory phenotype of CFD and FIBTEM was picked up.

The final fibrin clot has a highly heterogeneous structure, which is determined by both genetic and environmental factors [18]. Lower Fg concentrations increase bleeding risks due to formation of thicker fibrin fibers which are more susceptible to fibrinolysis. In contrast, abnormal structure of fibrin paradoxically increases thrombotic risk by impairing fibrin degradation by plasmin or facilitating clot fragmentation [18,19] and even enhancing TG due to poorly polymerizing fibrin [20]. Therefore, TG and other coagulation activation 
markers, such as prothrombin activation fragments, fibrin structure and consequences of the fibrinolytic system are of particular interest in CFD [21].

To our knowledge, this is the largest study reporting data on thrombin generation in CFD and the first study to assess the value of the ST Genesia ${ }^{\circledR}$ device in the context of CFD. TG seems to be affected by the abnormal fibrin structures as Fg activity levels correlated with most TG variables. One of the most important questions is whether ST Genesia ${ }^{\circledR}$ can help to identify the dysfibrinogenemia patients at the highest risk of thrombotic complications. Indeed, it could be that patients with the most decreased Fg activity have significantly higher ETP and peak height, and shortened lag time when challenged to low concentration of TF. Furthermore, in vivo TG was enhanced in patients with lower Fg levels, as occurs in a rare metabolic genetic disorder of lysinuric protein intolerance, LPI [21]. However, the clinical phenotype failed to be associated with TG variables. A more global approach taking also into account the fibrin clot structure including the capacity to make cross links may help to determine the heterogeneity of the clinical phenotype.

Only a few clinical studies explored non-conventional assays, such as thromboelastography (TEG) or ROTEM in predicting the clinical course of CFD. In these studies, TEG variables were affected by the causative mutations, but TEG failed to predict adverse events in most of the patients [11]. In one study, abnormal TEG results in non-pregnant women associated with an increased risk of obstetric complication during pregnancy [12]. One study on ROTEM showed that patients with dysfibrinogenemia have much higher median values of MCF than patients with hypodysfibrinogenemia [22], which may possibly reflect differences in the natural history of these disorders. This is in line with our observation as we found markedly abnormal median CT and CFT readings by FIBTEM in hypofibrinogenemia as compared to dysfibrinogenemia. Moreover, MCFs were significantly lower in the hypofibrinogenemia group than in dysfibrinogenemia according to all routine ROTEM tests used and correlated with Fg levels in all. Among them, FIBTEM MCF is of particular value to measure the contribution of Fg to the clot firmness, since cytochalasin D is first used to inactivate the platelets in the sample [23,24]. Here, on the other hand, the role of platelets remains obscure. Lower MCF readings in the patients such may reflect an impaired fibrin polymerization capacity. So far, no correlation between thromboelastometry and clinical phenotypes was demonstrated. Instead, in our subgroup analysis, we observed an association between the clinical phenotype of CFD and FIBTEM. Larger prospective studies are warranted to further validate and explore the mechanisms underlying these findings.

The spectrum of molecular abnormalities in CFD is broad, resulting in several subtypes of fibrinogen disorders with specific biological and clinical features [17]. Only a few fibrinogen variants are definitely associated with a clinical course. Thrombosis-related dysfibrinogenemia leads to a strong thrombotic phenotype, which usually is present in young adult with a thrombotic familial history [25]. A few fibrinogen mutations, clustered in exons 8 and 9 of $F G G$, cause fibrinogen deposit in endoplasmic reticulum, which in turn can give rise to liver failure [26]. However, in dysfibrinogenemia genotype cannot predict the bleeding risk. As confirmed by our observations, the individual range of TG variables was high without any correlation according to the site of fibrinogen mutation (FGA; A $\alpha$ chain vs. $\gamma$ chain). It is likely that besides fibrinogen variants, other relatively common genetic polymorphisms or epigenetics in coagulation and fibrinolytic pathways may affect the fibrin clot structure and therefore act as modifiers of the blood clot function in dysfibrinogenemia.

Our study is limited by the patient numbers, being too small to allow any further conclusions on the clinical phenotype vs. thrombin generation. Nevertheless, it presents a cohort of 22 CFD patients, as higher numbers are difficult to reach considering the relatively low prevalence of the disease and pre-analytical requirements for the TG assay.

In conclusion, our data suggests that ROTEM has a high sensitivity towards detection of hypofibrinogenemia. While the assessment of ROTEM, MCF, and especially FIBTEM may help to discriminate patients with hypo- or dysfibrinogenemia, its effectiveness 
in predicting the clinical phenotypes has to be confirmed on larger groups of patients. Our study suggests an inverse link between low fibrinogen activity levels and enhanced TG, likely including poor fibrin build-up which could modify the structure-function relationship of fibrin to support hemostasis. These similarities have been observed in other clinical inherited conditions such as FXIII deficiency and LPI with enhanced TG but overly expressed fibrinolysis.

\section{Materials and Methods}

Our study was conducted in accordance with the Declaration of Helsinki and approved by the relevant local institutional ethical committees (191/13/03/01/2014; 24 September 2014). All patients consented to take part in the study. The study included patients and their relatives with confirmed diagnosis of CFD from Helsinki, Finland (Coagulations Disorders Unit, Comprehensive Cancer Center, Helsinki University Hospital) and from Geneva, Switzerland (Division of Angiology and Hemostasis, University Hospitals of Geneva) between 2018 and 2020. CFD was classified based on the activity and antigen levels of $\mathrm{Fg}$ and genotype according to the International Society of Thrombosis and Hemostasis (ISTH) classification [8]. Symptoms of bleeding and/or thrombosis were recorded from the medical files. The bleeding score was evaluated by the ISTH bleeding assessment tool [27].

\subsection{Blood Sampling}

Fasting peripheral venous blood samples were collected under stable conditions at a time remote from acute infections, bleeds or surgeries, between 8-10 am into vacutainer tubes containing: (1) EDTA to measure blood cell counts and hemoglobin levels, and (2) sodium citrate (109 mM sodium citrate, 3.2\%, BD-Plymouth) for routine coagulation, TG and ROTEM.

\subsection{Coagulation Studies}

Citrated blood samples were centrifuged to isolate plasma and frozen in aliquots at $-70{ }^{\circ} \mathrm{C}$, if not tested immediately. Plasma levels of functional Fg were measured by the Clauss method using the HemosIL Fibrinogen activity (IL QFA Thrombin) on an ACL Top Analyzer or Multifibren U (Siemens, Marburg, Germany) on a BCS ${ }^{\circledR}$ XP coagulometer. Levels of total $\mathrm{Fg}$ antigen were measured by a latex immunoassay (Liaphen Fibrinogen, Hyphen BioMed, Neuville sur Oise, France) on a BCS ${ }^{\circledR} \mathrm{XP}$ coagulometer (Siemens, Germany).

Prothrombin time (PT; Owren method, Axis-Shield, Oslo, Norway), activated partial thromboplastin time (APTT; Actin FSL reagent) and thrombin time (Hemoclot Thrombin Time, Hyphen BioMed, France) were assessed in citrated plasma on an ACL Top Analyzer analyzer. Prothrombin fragments $(F 1+2)$ were measured by an enzyme immunoassay (Enzygnost ${ }^{\circledR} \mathrm{F} 1+2$, monoclonal, Siemens Healthcare Diagnostics, Marburg, Germany.

\subsection{DNA Preparation and Genetic Analysis}

Genomic DNA was extracted from fresh blood samples using standard procedures. Fibrinogen mutation screening was performed by PCR amplification of fibrinogen coding sequences and intron-exon junctions followed by Sanger sequencing (samples until 2019) or by whole exome sequencing performed at the Health 2030 Genome Centre at Campus Biotech, Geneva using Twist Core +Refseq Exome reagents. Variant calling was filtered for a panel of genes of the coagulation and fibrinolytic pathways, including the fibrinogen genes. Variant analysis was performed using the Ensembl Variant Effector Predictor (VEP) tool: http:/ / www.ensembl.org/Homo_sapiens/Tools/VEP (accessed on 1 December 2020). Mutations were confirmed by polymerase chain reaction (PCR) amplification of by sequencing as previously described [28]. According to guidelines of the Human Genome Variation society, mutations are reported with nucleotides numbered from the A in the ATG (Met) initiator codon and amino acids numbered from Met 1 [29]. 


\subsection{Thrombin Generation}

TG was measured in platelet-poor (PPP) plasma by using the novel, fully-automated ST Genesia ${ }^{\circledR}$ Analyzer (Diagnostica Stago S.A.S., Asnières-sur-Seine, France), which is based on the reference Calibrated Automated Thrombogram method [14]. PPP was prepared by double centrifugation at $2500 \times \mathrm{g}$ for $10 \mathrm{~min}$ at room temperature within $2 \mathrm{~h}$ of blood collection [14]. The assessment is based on measurement of fluorophore aminomethylcoumarin (AMC) generation, after adding a standard amount of human recombinant tissue factor and synthetic phospholipids to induce TG in the test plasma. AMC generation is monitored every $15-20 \mathrm{~s}$ at $450 \mathrm{~nm}$. All measurements were carried in duplicate by using two types of reagents: the STG ${ }^{\circledR}$-BleedScreen (STG-BLS, Stago, Asnières-sur-Seine, France and the $\mathrm{STG}^{\circledR}$-ThromboScreen (STG-TS, Stago, Asnières-surSeine, France). TG with the STG-BLS assay was triggered by a mixture of procoagulant phospholipids and low picomolar level of human tissue factor (TF), balanced for sensitivity to procoagulant factor deficiencies while minimizing contact activation. TG with the STG-TS assay was initiated by a mixture of procoagulant phospholipids and medium picomolar level of human TF in the presence or absence of TM, balanced for sensitivity to deficiencies in natural anticoagulants, without interfering contact activation. Since the addition of corn trypsin inhibitor upon blood collection did not make a difference in the data we are reporting the results obtained only in the citrated samples.

We followed endogenous thrombin potential (ETP), peak thrombin (peak height), lag time, and time to peak. Both absolute and normalized values of each TG parameter is provided. Normalization of each TG parameter is based on a reference plasma for each test aiming to reduce the interlaboratory variability as well as the variability between different measurement runs. We used standard human plasma in addition to the reference plasma TG levels provided by the manufacturer to assess TG in normal plasma.

\subsection{Rotational Thromboelastometry}

Thromboelastometry in whole blood was measured within $2 \mathrm{~h}$ of blood collection by ROTEM [30]. The standard INTEM, EXTEM, FIBTEM, and APTEM activation methods were performed by automated pipette program. We analyzed clotting time $(\mathrm{CT}, \mathrm{s})$ and maximum clot firmness (MCF, $\mathrm{mm}$ ). The reference ranges were: FIBTEM CT 46-84 $\mathrm{s}$ and MCF 6-21 mm, INTEM CT 161-204 s and MCF 51-69 mm; EXTEM CT 50-80 s, and MCF 55-72 mm; APTEM CT 41-80 s, and MCF 52-71 mm.

\subsection{Prothrombin Fragments $F 1+2$}

Circulating prothrombin fragments $(\mathrm{F} 1+2)$ were measured in plasma with Enzygnost ${ }^{\circledR}$ ELISA (Siemens). The manufacturer's reference ranges (5th to 95th percentiles) are 69-229 pmol/L.

\subsection{Statistical Analysis}

The recorded data are expressed as median and range. The significance of difference between two distinct data groups was examined with Mann-Whitney tests. The significance of difference between more groups was estimated by one-way analysis of variance (ANOVA). The correlation between two variables was measured using Spearman $r$ test. Calculations were performed with Prism 7.0 or 9.0 (GraphPad Software, La Jolla, CA, USA).

Author Contributions: A.C., T.S. and R.L. designed the study. The clinical data of the patients were collected by E.L., T.S. and A.C. T.S. and A.C. analyzed the data. M.N.A. was responsible for the genetic analysis. M.L. performed thrombin generation by ST Genesia ${ }^{\circledR}$. All authors contributed to the interpretation of the results. The first draft was written by T.S. and A.C. All authors contributed to and edited all subsequent drafts. All authors have read and agreed to the published version of the manuscript.

Funding: The study was supported by the Finnish Governmental grant, EVO no. 2019109 and Swiss National Science Foundation, grant no. 31003A_172864. 
Institutional Review Board Statement: The study was conducted according to the guidelines of the Declaration of Helsinki, and approved by the relevant local institutional ethical committees (Helsinki University Hospital and University Hospitals of Geneva).

Informed Consent Statement: Informed consent was obtained from all subjects involved in the study. Written informed consent has been obtained from the patient(s) to publish this paper.

Data Availability Statement: The data presented in this study are available on request from the corresponding author.

Acknowledgments: We acknowledge our patients for their participation to this study. We thank Stago for making the Genesia analyzer available for the study and providing all reagents.

Conflicts of Interest: The authors declare no conflict of interest.

\section{References}

1. De Moerloose, P.; Casini, A.; Neerman-Arbez, M. Congenital Fibrinogen Disorders: An Update. Semin. Thromb. Hemost. 2013, 39, 585-595. [CrossRef] [PubMed]

2. Neerman-Arbez, M.; De Moerloose, P.; Casini, A. Laboratory and Genetic Investigation of Mutations Accounting for Congenital Fibrinogen Disorders. Semin. Thromb. Hemost. 2016, 42, 356-365. [CrossRef] [PubMed]

3. Casini, A.; Brungs, T.; Lavenu-Bombled, C.; Vilar, R.; Neerman-Arbez, M.; De Moerloose, P. Genetics, diagnosis and clinical features of congenital hypodysfibrinogenemia: A systematic literature review and report of a novel mutation. J. Thromb. Haemost. 2017, 15, 876-888. [CrossRef] [PubMed]

4. Peyvandi, F.; Palla, R.; Menegatti, M.; Siboni, S.M.; Halimeh, S.; Faeser, B.; Pergantou, H.; Platokouki, H.; Giangrande, P.; Peerlinck, K.; et al. Coagulation factor activity and clinical bleeding severity in rare bleeding disorders: Results from the European Network of Rare Bleeding Disorders. J. Thromb. Haemost. 2012, 10, 615-621. [CrossRef] [PubMed]

5. Casini, A.; De Moerloose, P. the Congenital Fibrinogen Disorders Group Management of congenital quantitative fibrinogen disorders: A Delphi consensus. Haemophilia 2016, 22, 898-905. [CrossRef]

6. Krammer, B.; Anders, O.; Nagel, H.-R.; Burstein, C.; Steiner, M. Screening of dysfibrinogenaemia using the fibrinogen function versus antigen concentration ratio. Thromb. Res. 1994, 76, 577-579. [CrossRef]

7. Cunningham, M.T.; Brandt, J.T.; Laposata, M.; Olson, J.D. Laboratory Diagnosis of Dysfibrinogenemia. Arch. Pathol. Lab. Med. 2002, 126, 499-505. [CrossRef]

8. Casini, A.; Undas, A.; Palla, R.; Thachil, J.; De Moerloose, P. Diagnosis and classification of congenital fibrinogen disorders: Communication from the SSC of the ISTH. J. Thromb. Haemost. 2018, 16, 1887-1890. [CrossRef]

9. Desborough, M.J.R.; Jairath, V. Thrombelastography-guided blood product use before invasive procedures in cirrhosis with severe coagulopathy. Hepatology 2016, 64, 682-683. [CrossRef]

10. Levi, M.; Hunt, B.J. A critical appraisal of point-of-care coagulation testing in critically ill patients. J. Thromb. Haemost. 2015, 13, 1960-1967. [CrossRef]

11. Galanakis, D.K.; Neerman-Arbez, M.; Brennan, S.; Rafailovich, M.; Hyder, L.; Travlou, O.; Papadakis, E.; Manco-Johnson, M.J.; Henschen, A.; Scharrer, I. Thromboelastographic phenotypes of fibrinogen and its variants: Clinical and non-clinical implications. Thromb. Res. 2014, 133, 1115-1123. [CrossRef]

12. Zhou, J.; Xin, Y.; Ding, Q.; Jiang, L.; Chen, Y.; Dai, J.; Lu, Y.; Wu, X.; Liang, Q.; Wang, H.; et al. Thromboelastography predicts risks of obstetric complication occurrence in (hypo)dysfibrinogenemia patients under non-pregnant state. Clin. Exp. Pharmacol. Physiol. 2016, 43, 149-156. [CrossRef]

13. Zhou, J.; Ding, Q.; Chen, Y.; Ouyang, Q.; Jiang, L.; Dai, J.; Lu, Y.; Wu, X.; Liang, Q.; Wang, H.; et al. Clinical features and molecular basis of 102 Chinese patients with congenital dysfibrinogenemia. Blood Cells Mol. Dis. 2015, 55, 308-315. [CrossRef]

14. Hemker, H.C.; Giesen, P.; Al Dieri, R.; Regnault, V.; De Smedt, E.; Wagenvoord, R.; Lecompte, T.; Béguin, S. Calibrated Automated Thrombin Generation Measurement in Clotting Plasma. Pathophysiol. Haemost. Thromb. 2003, 33, 4-15. [CrossRef]

15. Bouvier, S.; Chea, M.; Ripart, S.; Hanss, M.; De Mazancourt, P.; Gris, J.-C. Successful Pregnancy under Fibrinogen Substitution with Heparin and Aspirin in a Woman with Dysfibrinogenemia Revealed by Placental Abruption. Thromb. Haemost. 2018, 118, 2006-2008. [CrossRef]

16. Calzavarini, S.; Brodard, J.; Angelillo-Scherrer, A.; Quarroz, C.; Maire, L.; Nützi, R.; Jankovic, J.; Rotondo, L.C.; Giabbani, E.; Fiedler, G.M.; et al. Thrombin generation measurement using the ST Genesia Thrombin Generation System in a cohort of healthy adults: Normal values and variability. Res. Pract. Thromb. Haemost. 2019, 3, 758-768. [CrossRef]

17. Rubbia-Brandt, L.; Neerman-Arbez, M.; Rougemont, A.-L.; Malé, P.-J.; Spahr, L. Fibrinogen Gamma375 Arg $\rightarrow$ Trp Mutation (Fibrinogen Aguadilla) Causes Hereditary Hypofibrinogenemia, Hepatic Endoplasmic Reticulum Storage Disease and Cirrhosis. Am. J. Surg. Pathol. 2006, 30, 906-911. [CrossRef] [PubMed]

18. Zabczyk, M.; Undas, A. Plasma fibrin clot structure and thromboembolism: Clinical implications. Pol. Arch. Intern. Med. 2017, 127, 873-881. [CrossRef]

19. Undas, A.; Zabczyk, M. Antithrombotic medications and their impact on fibrin clot structure and function. J. Physiol. Pharmacol. Off. J. Pol. Physiol. Soc. 2018, 69. [CrossRef] 
20. Pitkänen, H.H.; Jouppila, A.; Lemponen, M.; Ilmakunnas, M.; Ahonen, J.; Lassila, R. Factor XIII deficiency enhances thrombin generation due to impaired fibrin polymerization-An effect corrected by Factor XIII replacement. Thromb. Res. 2017, $149,56-61$. [CrossRef] [PubMed]

21. Pitkänen, H.H.; Kärki, M.; Lassila, R.; Niinikoski, H.; Tanner, L.; Näntö-Salonen, K.; Pikta, M.; Kopatz, W.F.; Zuurveld, M.; Meijers, J.C.M.; et al. Abnormal coagulation and enhanced fibrinolysis due to lysinuric protein intolerance associates with bleeds and renal impairment. Haemophilia 2018, 24, e312-e321. [CrossRef]

22. Treliński, J.; Pachniewska, K.; Matczak, J.; Nowak, P.; Robak, M.; Chojnowski, K. Assessment of Selected ROTEM Parameters, Kinetics of Fibrinogen Polymerization and Plasmin Amidolytic Activity in Patients with Congenital Fibrinogen Defects. Adv. Clin. Exp. Med. 2016, 25, 1255-1263. [CrossRef]

23. Dupuy, E.; Soria, C.; Molho, P.; Zini, J.-M.; Rosenstingl, S.; Laurian, C.; Bruneval, P.; Tobelem, G. Embolized ischemic lesions of toes in an afibrinogenemic patient: Possible relevance to in vivo circulating thrombin. Thromb. Res. 2001, 102, 211-219. [CrossRef]

24. Solomon, C.; Rahe-Meyer, N.; Schöchl, H.; Ranucci, M.; Görlinger, K. Effect of haematocrit on fibrin-based clot firmness in the FIBTEM test. Blood Transfus. 2013, 11, 412-418.

25. Haverkate, F.; Samama, M. Familial dysfibrinogenemia and thrombophilia. Report on a study of the SSC Subcommittee on Fibrinogen. Thromb Haemost. 1995, 73, 151-161.

26. Callea, F.; Giovannoni, I.; Sari, S.; Guldal, E.; Dalgic, B.; Akyol, G.; Sogo, T.; Al-Hussaini, A.; Maggiore, G.; Bartuli, A.; et al. Fibrinogen Gamma Chain Mutations Provoke Fibrinogen and Apolipoprotein B Plasma Deficiency and Liver Storage. Int. J. Mol. Sci. 2017, 18, 2717. [CrossRef] [PubMed]

27. Rodeghiero, F.; Tosetto, A.; Abshire, T.C.; Arnold, D.M.; Coller, B.S.; James, P.D.; Neunert, C.E.; Lillicrap, D.; ISTH/SSC joint VWF; Perinatal/Pediatric Hemostasis Subcommittees Working Group. ISTH/SSC bleeding assessment tool: A standardized questionnaire and a proposal for a new bleeding score for inherited bleeding disorders. J. Thromb. Haemost. 2010, 8, $2063-2065$. [CrossRef] [PubMed]

28. Neerman-Arbez, M.; De Moerloose, B.C.; Honsberger, A.; Schönbörner, A.; Rossier, C.; Peerlinck, K.; Claeyssens, S.; Di Michele, D.; D'Oiron, R.; Dreyfus, M.; et al. Mutations in the fibrinogen A $\alpha$ gene account for the majority of cases of congenital afibrinogenemia. Blood 2000, 96, 149-152. [CrossRef]

29. Dunnen, J.T.D.; Antonarakis, S.E. Nomenclature for the description of human sequence variations. Hum. Genet. 2001, 109, 121-124. [CrossRef]

30. Chitlur, M.; Rivard, G.E.; Lillicrap, D.; Mann, K.; Shima, M.; Young, G.; on the behalf of the Factor VIII, Factor IX, and Rare Coagulation Disorders Subcommittee of the Scientific and Standardisation Committee of the International Society on Thrombosis and Haemostasis. Recommendations for performing thromboelastography/thromboelastometry in hemophilia: Communication from the SSC of the ISTH. J. Thromb. Haemost. 2014, 12, 103-106. [CrossRef] [PubMed] 